Bangladesh J. Plant Taxon. 13(1): 49-54, 2006 (June)

\title{
IDENTIFICATION OF SOME HIBISCUS GERMPLASM THROUGH NUMERICAL ANALYSIS
}

\author{
Nazmul Alam ${ }^{1}$, Mostafa Kamal Pasha and Shamsuddin Ahmad ${ }^{2}$ \\ Department of Botany, Chittagong University, Chittagong-4331, Bangladesh
}

Key words : Hibiscus, Numerical analysis, Identification, Cluster analysis, Dendrogram

\begin{abstract}
Numerical analyses of 68 morphological characters of 12 varieties/forms belonging to four species of Hibiscus were carried out by calculating Sørensens and Sneath and Sokal similarity coefficients followed by cluster analysis and construction of dendrograms for visual appreciation of taxonomic relationship within this family. The Sørensens similarity coefficient varied between 0.211 and 0.919 and Sneath and Sokal similarity coefficient ranged between 0.142 and 0.890 , indicating much variation between the species.
\end{abstract}

\section{Introduction}

The genus Hibiscus Medik. of family Malvaceae exhibits considerable taxonomic complexity. In Bangladesh, Hibiscus cannabinus L. (Deccan hemp or Kenaf) and $H$. sabdariffa L. (Rosella or Mesta), are cultivated and H. acetosella L. and H. radiatus L. are wild. In recent years $H$. cannabinus and $H$. sabdariffa are getting much attention and grown commercially for paper-pulp production in many countries (Andrew and Piters 1980, Nieschlag et al. 1960). In Bangladesh, paper and pulp mills have recently introduced Kenaf (H. cannabinus) along with jute whole stem as raw materials for paper and pulp making (Anonymous 1993). This new use has led to investigate about the component characters contributing to biomass production of the above four species. The fibre of jute (Corchorus capsularis and C. olitorius), Kenaf (H. cannabinus) and Mesta ( $H$. sabdariffa) are considered as economic yield for textile purpose, while air dry whole stem is considered as biomass in paper-pulp industries (Kalder 1991).

Despite the high socio-economic significance no major breakthrough has been achieved in research relating to these above species. Numerical approaches have not been utilized for taxonomic purposes among other taxa of the Malvaceae even though there seems to be ample scope for an examination of the applicability of these techniques to an assessment of the taxonomic relatedness of the taxa belonging to this family. The present investigation was, therefore, undertaken to determine the taxonomic relationship by using numerical analyses of 12 taxa at intraspecific and infraspecific levels.

${ }^{1}$ Department of Botany, Jahangirnagar University, Savar, Dhaka-1342, Bangladesh. ${ }^{2}$ Bangladesh Jute Research Institute, Shere-e-Bangla Nagar, Dhaka, Bangladesh. 


\section{Materials and Methods}

Three cultivars of Hibiscus cannabinus viz., HC-95, HC-2 and CP1 72126/1; four of H. sabdariffa viz., var. HS 24, breeding line 300M, cultivar 2065 and cultivar Samu 93; three forms of $H$. acetosella viz., Green Foliage Yellow Flower (GFYF), Green Foliage Magenta Flower (GFMF) and acc. Red Foliage Crimson red flower (RFCRF) and two forms of $H$. radiatus viz., Tall with magenta flower and Dwarf with yellow flower were taken. The experiment was conducted at central station of BJRI, Dhaka. The experiment was laid out in a randomized complete block design (RBD) with three replications in each case. Recommended doses of fertilizers, irrigation, weeding, mulching and other cultural practices were performed as and when required.

Hierarchical cluster analysis for qualitative characters was performed following Binary Euclidian distance and Dendrogram was drawn using average linkage (between groups). Among the various morphological features qualitative characters of plant were used in cluster analysis and constructing dendrograms. Sixty-eight morphological characters were selected without any prejudices for each variety (Table 1). The similarity coefficients of different OTU's were measured according to Sørensens (1948) and Sneath and Sokal (1973). The coefficients were clustered by UPGMA method as outlined by Sneath and Sokal (1973). All the analyses were computed using the software SPSS 10.0.1 standard version (Statistical Package for Social Sciences) released in 1999. The program was run through Windows 98 operating system, in a Pentium III model computer.

\section{Results and Discussion}

Based on 68 qualitative characters (Table 1), the similarity coefficients for each pair OTU's (operational taxonomic units) were calculated separately according to both Sørensens (1948) and Sneath and Sokal (1973) similarity measure and the data matrices were prepared. Based on these matrices dendrograms were constructed.

In both similarity matrices prepared from the values of the taxa examined showed that a few of the taxa have similarity coefficient greater than 0.50 with respect to the other taxa. The Sørensens's similarity coefficients varied between 0.211 and 0.919 while the Sneath and Sokal similarity coefficients ranged between 0.142 and 0.890 (Table 2). The Sørensens's similarity coefficient for within species ranged between 0.595 and 0.919, 0.211 and $0.595,0.378$ and 0.667 and 0.619 for $H$. cannabinus, $H$. sabdariffa, $H$. acetosella and $H$. radiatus respectively. Whereas the Sneath and Sokal similarity coefficient ranged for the above-mentioned case were 0.499 to $0.890,0.142$ to 0.501 , 0.285 to 0.580 and 0.506 respectively (Table 2).

Considering the OTU's coefficient of similarity matrix, $H$. sabdariffa showed little intervarietal relationship. The cult. CPI 72126/1 and var. HC 2 of $H$. cannabinus showed maximum coefficient value (0.890) and was followed by $0.741,0.658$ for cult. Samu 93 
and var. HC 95, and breeding line 300M and var. HC 95 of $H$. sabdariffa and $H$. cannabinus, respectively (Table 2).

Table 1. Characters used for construction of matrix of similarity coefficient among 12 taxa of Hibiscus (including varieties/forms) of Malvaceae family.

\begin{tabular}{|c|c|c|c|}
\hline Characters & Variations & Characters & Variations \\
\hline \multirow{4}{*}{ 1. Stem color: } & Green & 12. Leaf shape: & Entire \\
\hline & Full green & & Partially lobed \\
\hline & Red & & Deeply lobed \\
\hline & Green pigmented & 13. Leaf pubescence: & Present/Absent \\
\hline \multirow[t]{4}{*}{ 2. Leaf lamina color: } & Green & 14. Leaf pubescence types: & Not prickled \\
\hline & Full green & & Sparsely prickled \\
\hline & Red & $\begin{array}{l}\text { 15. Pigmentation of flower } \\
\text { buds: }\end{array}$ & Green \\
\hline & Green pigmented & & Green pigmented \\
\hline \multirow[t]{4}{*}{ 3. Leaf vein color: } & Green & & Red \\
\hline & Full green & $\begin{array}{l}\text { 16. Flower petal color } \\
\text { (Outer): }\end{array}$ & Yellow \\
\hline & Red & & Magenta \\
\hline & Green pigmented & & Pink \\
\hline \multirow[t]{4}{*}{ 4. Leaf petiole color: } & Green & & Crimson red \\
\hline & Full green & 17. Flower color (Inner): & Yellow \\
\hline & Red & & Magenta \\
\hline & Green pigmented & & Pink \\
\hline 5. Stipule +/-: & Stipulate/Exstipulate & & Deep magenta \\
\hline \multirow[t]{3}{*}{ 6. Stipule shape: } & Foliaceous & & $\begin{array}{l}\text { Yellow lower center } \\
\text { red }\end{array}$ \\
\hline & Scally & & Pink lower center red \\
\hline & Filiform & 18. Pigmentation of fruit: & Green \\
\hline \multirow[t]{4}{*}{ 7. Stipule color: } & Green & & Green pigmented \\
\hline & Full green & & Red \\
\hline & Red & 19. Fruit pubescence: & Smooth \\
\hline & Green pigmented & & Hairy \\
\hline 8. Stem pubescence: & Present/Absent & & Bristle \\
\hline \multirow[t]{3}{*}{ 9. Stem pubescence type: } & Smooth & $\begin{array}{l}\text { 20. Seed dispersal } \\
\text { mechanism: }\end{array}$ & $\begin{array}{l}\text { Dehiscent/ Non- } \\
\text { debiscent }\end{array}$ \\
\hline & Hairy & 21. Seed coat color: & Brown \\
\hline & Prickly & & Brownish grey \\
\hline 10. Branching habit: & $\begin{array}{l}\text { Branched } \\
\text { Unbranched }\end{array}$ & & Grey \\
\hline 11. Branching habit type: & $\begin{array}{l}\text { No branching } \\
\text { Weak } \\
\text { Intermediate } \\
\text { Strong } \\
\text { Very strong }\end{array}$ & & \\
\hline
\end{tabular}


Table 2. Range of coefficients of similarity matrix following Sneath and Sokal similarity measure among four species of Hibiscus.

\begin{tabular}{|c|c|c|c|c|c|}
\hline \multicolumn{2}{|c|}{ Sources of variation } & H. cannabinus & H. sabdariffa & H. acetosella & H. radiatus \\
\hline \multicolumn{2}{|c|}{$\begin{array}{l}\text { Intraspecies } \\
\text { (within varieties and forms) }\end{array}$} & $\begin{array}{c}0.595-0.919 \\
(0.499-0.890)\end{array}$ & $\begin{array}{c}0.211-0.595 \\
(0142-0.501)\end{array}$ & $\begin{array}{c}0.378-0.667 \\
(02.85-0.580)\end{array}$ & $\begin{array}{c}0.619 \\
(0.506)\end{array}$ \\
\hline \multirow{4}{*}{$\begin{array}{l}\text { Interspecies } \\
\text { (between } \\
\text { species) }\end{array}$} & H. cannabinus & - & $\begin{array}{c}0.222-0.800 \\
(0.156-0.741)\end{array}$ & $\begin{array}{c}0.162-0.541 \\
(0.142-0.442)\end{array}$ & $\begin{array}{c}0.410-0.500 \\
(0.308-0.407)\end{array}$ \\
\hline & H. sabdariffa & - & - & $\begin{array}{c}0.205-0571 \\
(0.135-0.481)\end{array}$ & $\begin{array}{c}0.205-0.634 \\
(0.136-0.527)\end{array}$ \\
\hline & H. acetosella & - & - & - & $\begin{array}{c}0.462-0.615 \\
(0.356-0.516)\end{array}$ \\
\hline & H. radiatus & - & - & - & - \\
\hline
\end{tabular}

Note: Data in parenthesis are coefficients resulted from Sneath and Sokal similarity measure. Coefficients calculated following Sørensens similarity measure.

While the minimum coefficient value was observed between form RFCRF of $H$. acetosella and breeding line $300 \mathrm{M}$ of $\mathrm{H}$. sabdariffa. However, some of the intervarietal similarity coefficients were found between 0.501 and 0.582 , but maximum of them ranged between 0.135 and 0.481 . At the intervarietal level, similarity coefficients value greater than 0.50 recorded in comparisons involving cult. CP1 72126/1 and var. HC 95, breeding line 300M and cult. Samu 93, form RFCRF and cult. 2065, form Dwarf and breeding line 300M, GFYF and GFMF forms, Tall and GFMF forms, and Tall and Dwarf forms. Here, comparisons were based on Sneath and Sokal's similarity coefficient values. Sørensens’s similarity coefficients always gave relatively higher values in each case.

The phenetic relationship among the taxa studied can be visualized in the dendograms. The patterns of dendrograms prepared according to Sørensen's measure were found to be almost identical with Sneath and Sokal's one with minor exceptions.

In all the approaches var. HC 2 and cult. CPI 72126/1 of $H$. cannabinus exhibited the highest similarity and clustered together (Figs.1 and 2). Similar kinds of clustering were also observed between var. HC 95 of $H$. cannabinus and cult. Samu 93 of H. sabdariffa. Similarity between GFYF and GFMF forms of $H$. acetosella was greater than those observed between Tall and Dwarf forms of $H$. radiatus. Cultivar 2065 of $H$. sabdariffa and form RFCRF of $H$. acetosella clustered further away apart from the members of their respective species.

All the three members of $H$. cannabinus together with cult. Samu 93 and breeding line $300 \mathrm{M}$ of $H$. sabdariffa formed a cluster equal to the distance of the cluster formed by GFYF and GFMF forms of $H$. acetosella and Dwarf and Tall forms of $H$. radiatus. Var. HS 24 of $H$. sabdariffa exhibited different type of grouping with the other members of Hibiscus. 
Fig. 1. Dendrogram using Sørensen's measure with average Linkage (between groups).

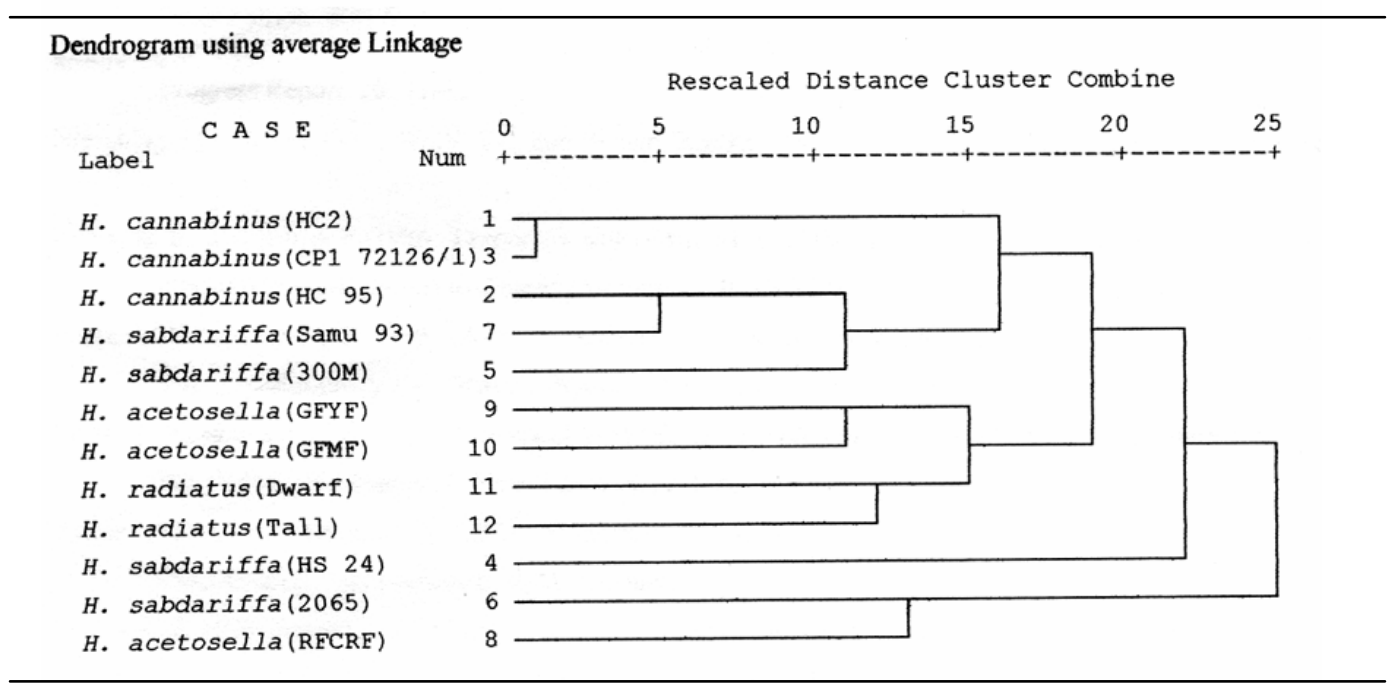

Fig. 2. Dendrogram using Sneath and Sokal similarity matrix with average Linkage (between groups).

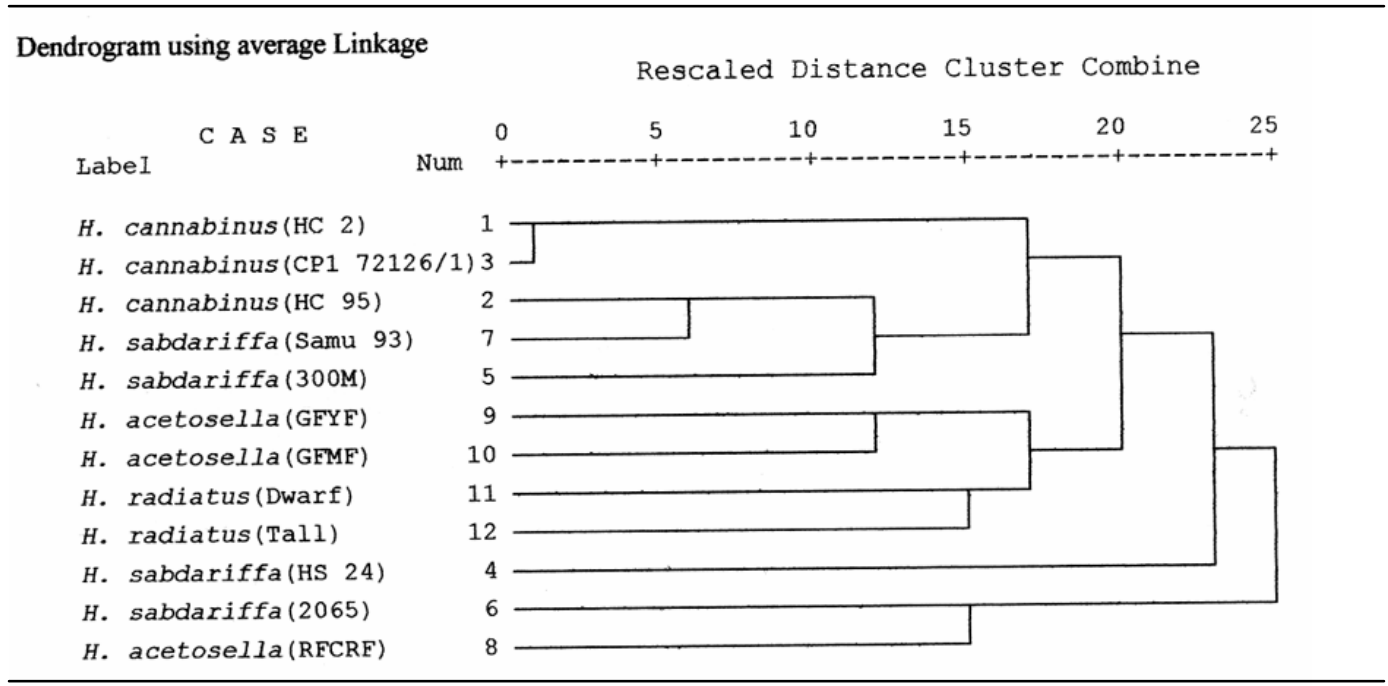

In all the three approaches of clustering (namely Sørensen's and Sneath and Sokal ), var. HS 24 of $H$. sabdariffa grouped with the cluster formed by the rest at distance greater than 20 and later joined with the cluster formed by cult. 2065 of $H$. sabdariffa and form RFCRF of $H$. acetosella at distance 25 (Fig. 1 and 2). Pasha and Sen (1986, 1995, 1997) also worked on several taxa of Cucurbitaceae. In numerical analysis they have 
constructed dendrograms on the basis of Jaccards (1908) and Sørensen’s (1948) similarity coefficient of 143 characters. The similarity coefficient of the 22 taxa varied between 0.36 and 0.91 indicated different levels of diversity among those species.

\section{References}

Andrew, C.S. and Piters, W.H.J. 1980. Foliar symptoms of mineral disorders in Kenaf (Hibiscus cannabinus L.). CISRO, Aust. Div. Trop. Crops past. Tech. Rep. 22: 1-2.

Annonymous, 1993. Paper and pulp from green jute and allied fibre. In: Jute Newsletter of International Jute Organization. 8(4): 6.

Jaccards, P. 1908. Nouvelles recherches sur la distribution florale. Bull. Soc. vaud. Sci. Nat. 44: 223-270.

Kalder, A.F. 1991. A competitive fibre plantation eucalypt based on recent investigation in Thailand. TAPPI Progress Report. 20: 77-82.

Nieschlag, H.J., Nelsa, G.H., Wolff, I.A. and Perdue, R.E.Jr. 1960. A search for new fibre crops. TAPPI, 43(4): 193-201.

Pasha, M.K. and Sen, S.P. 1986. Taxonomy and relationship of the cucurbitaceae with particular reference to palynological, numerical and molecular aspects. Ph.D. Thesis, Kalyani University, India.

Pasha, M.K. and Sen, S.P. 1995. Molecular analysis of Cucurbitaceae genome: Reassociation kinetic classes and its evolutionary significance. Biochem. Syst. Ecol. 23(4): 399-406.

Pasha, M.K. and Sen, S.P. 1997. Numerical analysis in the taxonomy of Cucurbitaceae of Eastern India and Bangladesh. Bangladesh J. Plant Taxon. 4(1): 1-12.

Sneath, P.H.A. and Sokal, R.R. 1973. Numerical Taxonomy: The Principles and Practice of Numerical Classification. San Francisco: W.H. Freeman.

Sørensen, T. 1948. A method of establishing groups of equal amplitude in plant sociology based on similarity of species content. Biol. Skr., K. danske Vidensk. Selsk. 5: 1-34. 